\title{
CONHECIMENTO E OPINIÕES DE ALUNOS DA ETAPA FINAL DO \\ ENSINO MÉDIO SOBRE TRANSGÊNICOS
}

Nayara Mara de Meneses Silva

Bióloga pelo UNIFOR-MG

Lília Rosário Ribeiro

Professora do UNIFOR-MG

Mestre em Genética e Melhoramento de Plantas pela UFLA

\begin{abstract}
RESUMO
Com o advento da engenharia genética na década de 70, foi possível a obtenção dos organismos transgênicos, um considerável avanço biotecnológico que trouxe muitos benefícios em diversas áreas e também alguns malefícios. Pesquisas realizadas com estudantes da etapa final da educação básica demonstraram uma grande dificuldade na construção de conceitos e na formulação do pensamento biológico. O presente trabalho objetivou a realização de uma pesquisa de campo sobre os conhecimentos e opiniões de estudantes do ensino médio sobre os transgênicos. A coleta de dados foi feita através de questionários, aplicados a 300 estudantes do $3^{\circ}$ ano do ensino médio de três escolas estaduais do município de Formiga-MG. A análise de dados foi feita por meio de estatística descritiva e demonstrou que tais estudantes não possuem conhecimentos bem definidos sobre os transgênicos, elaborando respostas controversas e equivocadas a respeito desse tema.
\end{abstract}

Palavras-chave: Biotecnologia. Ensino da biologia. Transgênicos.

\section{KNOWLEDGE AND OPINIONS OF THE STUDENTS AT THE FINAL STAGE OF HIGH SCHOOL ON TRANSGENICS}

\begin{abstract}
With the advent of genetic engineering in the 70's, it was possible to obtain the transgenic organisms, a considerable step forward that biotechnology has brought many benefits in several areas and also some harm. Researches conducted with students in the final stage of basic education showed a big difficulty in the construction of concepts and the formulation of biological thoughts. This work aimed at achieving a survey on the knowledge and opinions of students in high school on transgenics. The data collection was done through questionnaires that were applied to 300 students from third year of high school of three public schools in the city of Formiga - MG. The data analysis was done by descriptive statistics, and demonstrated that these students do not have clear knowledge about transgenics, producing controversial and wrong answers about this topic.
\end{abstract}

Keywords: Biotechnology. Teaching of biology. Transgenics. 


\section{INTRODUÇÃO}

A descoberta da tecnologia do DNA recombinante e o desenvolvimento da engenharia genética na década de 70 permitiram a modificação direta do genoma de um organismo, pela introdução de um gene exógeno ou pela inativação de um gene já existente. Realizado esse processo, o novo gene passa a comandar a produção de suas substâncias no organismo modificado, o que possibilita mudanças, por exemplo, na qualidade dos alimentos. (ALVES, 2004).

Perante tantas modificações, a população em geral é convocada a refletir e opinar sobre benefícios, riscos e implicações éticas, morais e sociais provenientes das biotecnologias geradas por essas pesquisas. (PEDRANCINI et al, 2008). No entanto, é notório o despreparo científico da população em geral, inclusive de estudantes para participar de forma crítica e democrática, de debates sobre os avanços biotecnológicos. (LEITE, 2000).

Estudos sobre os processos de ensino aprendizagem de ciências revelam que os alunos apresentam conceitos intuitivos, espontâneos que são adquiridos na vivência diária, em ambientes não escolares e que em boa parte se distanciam dos conhecimentos científicos, estabelecendo-se como um obstáculo à aprendizagem desses conhecimentos. No entanto, as ideias alternativas dos alunos podem ser um ponto de partida para o aprendizado do saber científico, em atividades didáticas planejadas e intencionalmente desenvolvidas. (BIZZO, 1999).

Pesquisas recentes mostram que alunos na fase final do ensino médio, e muitos que já concluíram a educação básica, continuam emitindo explicações limitadas às propriedades sensoriais de vários fenômenos tais como a transgenia. Dessa forma, é observável que, mesmo na atualidade em que vivemos com ricas descobertas científicas e tecnológicas, discutidas no âmbito escolar, divulgadas no meio acadêmico de modo a fazerem parte do cotidiano, a população se encontra claramente despreparada. Essa realidade demonstra que nem sempre os conhecimentos adquiridos na escola possibilitam que os sujeitos ultrapassem o saber de senso comum ou as primeiras impressões adquiridas na vivência. (PEDRANCINI et al, 2007).

Neste cenário, a escola não pode mais se limitar à transmissão de um programa de conhecimentos enciclopédicos, que são retidos temporariamente pelos alunos. Deve trabalhar com conhecimentos de modo a serem generalizados para a resolução de problemas e entendimento de situações da atualidade, deve abordar a ciência de forma transdisciplinar e contextualizada, a fim de promover uma educação que possibilite aos cidadãos tirar suas próprias decisões conscientes e esclarecidas. (PEDRANCINI et al, 2008).

Considerando tais premissas, o presente trabalho teve como objetivo, a realização de um estudo de campo sobre o conhecimento dos estudantes do $3^{\circ}$ ano do ensino médio de três escolas estaduais do município de Formiga, sobre os transgênicos, suas opiniões sobre as utilidades, aplicações e implicações 
dessa biotecnologia, tendo em vista a educação escolar.

\section{MATERIAIS E MÉTODOS}

Este trabalho foi realizado em três escolas estaduais do município de Formiga-MG. O projeto de pesquisa referente ao trabalho foi submetido e aprovado pelo Comitê de Ética em Pesquisa do UNIFORMG, obedecendo a todos os princípios éticos.

Foram selecionados para participarem da pesquisa, somente alunos do $3^{\circ}$ ano do ensino médio, por estarem concluindo a educação básica. A amostra total foi composta de 300 alunos, 100 de cada escola, sendo que os participantes foram definidos através de sorteio simples. Para a coleta de dados, foi elaborado um questionário contendo oito questões objetivas e duas dissertativas que incluem conceitos básicos e questões polêmicas sobre os transgênicos. Os dados foram analisados por meio de estatística descritiva.

\section{RESULTADOS E DISCUSSÕES}

Entre os estudantes que participaram da pesquisa, $80 \%$ revelaram saber o que é um transgênico. Quando os alunos foram questionados sobre como é feito um transgênico, constatou-se que apenas $32,7 \%$ dos alunos conhecem as etapas da construção de um transgênico.

Ao responderem a questão "você conhece algum transgênico", um alto índice de estudantes (75\%) disse conhecer. Na resposta à quarta questão, na qual estavam predefinidos alguns transgênicos, foram destacados entre os mais conhecidos pelos estudantes a soja $(33,4 \%)$, o milho $(17,7 \%)$ e o tomate $(14,6 \%)$.

É válido ressaltar que esses exemplos estão constantemente veiculados aos meios de comunicação, e se destacam pela sua produção em larga escala. $\mathrm{O}$ arroz $(8 \%)$, batata $(7,1 \%)$ e a cenoura $(6,7 \%)$ foram considerados, porém, em um número menor. A insulina e o hormônio do crescimento humano foram considerados por poucos estudantes, em pequenas porcentagens de 2,6\% e 2,3\% respectivamente.

Esses resultados corroboram com os de Pedrancini et al (2008) que dizem: "aquilo que é veiculado sem intenção explícita de explicar o que é um transgênico tem se sobressaído aos conhecimentos trabalhados na escola". É possível inferir ainda que as informações divulgadas em livros, revistas, jornais e outros meios de comunicação em massa, aliadas à forma de condução do ensino não estão sendo suficientes para garantir aos estudantes o entendimento do assunto. Esses resultados se apresentam em concordância com as ideias propostas por Pedrancini et al. (2007). Sobre essa questão, ressalta que, quando o aluno se apropria de uma palavra, na verdade ele não se apropria do conceito que 
essa palavra expressa, pois ele utiliza o mesmo termo com significados diferentes.

Quando os estudantes foram questionados sobre o consumo de algum transgênico, 59,7\% responderam já terem consumido produtos transgênicos. Considerando que $20 \%$ dos estudantes não sabem o que é um transgênico, e que $25 \%$ não conhecem nenhum transgênico, pode-se constatar que os dados fornecidos pelos estudantes são distorcidos e contraditórios, o que leva a reforçar a falta de preparo e conhecimento desses estudantes no que diz respeito aos transgênicos. Esses dados estão de acordo com os resultados Pedrancini et al (2008) que declararam que 44\% de seus entrevistados não sabem se fazem o consumo desses produtos.

Ao responderem à sexta questão, que questionava sobre os riscos trazidos pelos produtos transgênicos à saúde humana, destaca-se que a maioria dos entrevistados (57\%), afirmaram que esses produtos podem trazer riscos, $42 \%$ descartaram a possibilidade desses riscos e $1 \%$ revelou não saber responder a questão. Esses resultados se mostram de acordo com os resultados de Pedrancini et al (2008) que relatam que a saúde humana é um dos principais temas de debates e questionamentos sobre os riscos trazidos pelos transgênicos.

De acordo com Nodari e Guerra (2003), as novas características conferidas pelo transgene quanto aos seus impactos pouco são avaliadas, e ainda não foi gerada uma base de conhecimento adequada e suficiente para uma abordagem correta do assunto.

Sobre as vantagens dos transgênicos, foi destacado um elevado índice de estudantes $(37,2 \%)$ que não souberam responder e/ou revelaram não conhecer as vantagens geradas por essa biotecnologia, e entre as respostas por eles mais consideradas estão: a resistência a pragas (17,3\%); maior produtividade $(16,7 \%)$; a facilidade de produção (7,5\%); a melhor aparência dos alimentos $(6,2 \%)$; o aumento do valor nutricional dos alimentos (5,5\%); a melhoria da qualidade geral (5\%). Alguns estudantes $(4,6 \%)$ relataram que os transgênicos não possuem nenhuma vantagem.

Os resultados aqui apresentados corroboram com os estudos de Pedrancini et al (2008) que apontam a resistência a pragas, o aumento da produtividade e o aumento do valor nutricional dos alimentos como vantagens da técnica de transgenia. Sobre estes aspectos, Alves (2004), considera que os transgênicos têm se mostrado mais produtivos que as culturas convencionais; considera a alta resistência a pragas; aumento da produção de fármacos e o aumento do valor nutricional dos alimentos.

Sobre as desvantagens geradas por essa biotecnologia, a maioria $(48,1 \%)$ dos estudantes revelou não possuir conhecimento suficiente para a elaboração de resposta. Alguns estudantes destacaram os prejuízos à saúde (39\%), a incerteza sobre as futuras consequências da utilização dos transgênicos $(2,7 \%)$; a redução do valor nutricional dos alimentos $(2,4 \%)$; os prejuízos ao meio ambiente $(1,7 \%)$ e o fato de "os produtos deixarem de ser naturais" (1,7\%); a inexistência de desvantagens também foi relatada pelos estudantes $(4,4 \%)$.

Deve-se ressaltar que entre os alunos que declararam prejuízos ao meio ambiente, apenas dois 
alunos apresentaram respostas bem elaboradas e coerentes, apontando fatores como o desequilíbrio ecológico e as possíveis contaminações gênicas de populações de plantas selvagens.

Em se tratando de meio ambiente, são polêmicos os debates no que se refere às ameaças à biodiversidade devido ao fluxo gênico, trazendo, como consequência, deslocamento ou eliminação de espécies silvestres, poluição e erosão genética. (NODARI; GUERRA, 2003). Apesar da maioria dos alunos ter enfocado a saúde e o meio ambiente, merece destaque o relato de um aluno que abordou sobre as implicações socioeconômicas, em que ele menciona uma maior vantagem dos países desenvolvidos na aquisição de conhecimento e no desenvolvimento dessa biotecnologia.

Quando os alunos foram solicitados a se posicionarem a favor ou contra os transgênicos, uma pequena diferença (1\%) foi observada entre aqueles que se declararam a favor $(48,7 \%)$ e contra $(47,7 \%)$. Uma pequena parcela dos entrevistados declarou não saber opinar acerca dessa questão (3,6\%). Observa-se que as respostas são controversas, e que os alunos não possuem argumentos convincentes para se posicionarem perante esse assunto. Leite (2000) relata que é notório o despreparo científico da população em geral, inclusive dos estudantes para participar de forma crítica e democrática em debates sobre os avanços biotecnológicos.

Enfim, quando questionados sobre onde eles adquiriram seus conhecimentos a respeito dos transgênicos, a televisão teve o maior destaque entre as respostas por eles apresentadas $(34,8 \%)$, seguida da escola (30,6\%). Alguns estudantes mostraram terem adquirido seus conhecimentos por meio da internet $(11 \%)$, outros através de revistas $(9,4 \%)$, alguns estudantes declararam que seus conhecimentos são advindos de jornais $(8,6 \%)$. Já o livro foi relatado por poucos alunos $(2,5 \%)$, e alguns declararam não terem conhecimento acerca do assunto $(3,1 \%)$.

Dentre os alunos que declararam terem aprendido sobre esse tema na escola, um deles declarou que os conhecimentos foram transmitidos pelos colegas, e um outro aluno revelou ter aprendido sobre o assunto com o presente trabalho.

\section{CONCLUSÃO}

Os conhecimentos e opiniões declarados pelos estudantes da etapa final do ensino médio em relação aos transgênicos revelaram um claro despreparo na compreensão do tema abordado. Essas dificuldades podem estar relacionadas a uma escolha inadequada da prática pedagógica utilizada para a apresentação desse tema. Tais estudantes parecem não trazer consigo um bom embasamento científico a esse respeito, uma vez que os conhecimentos ensinados na escola parecem não viabilizar aos estudantes uma educação que os estimule a pensar e tirar suas próprias conclusões de forma consciente e esclarecida. 


\section{REFERÊNCIAS}

ALVES, G. S. A Biotecnologia dos transgênicos: preocupação é a palavra de ordem. Natal: Outubro, 2004.

BIZZO, N.; KAWASAKI, C. S. Este artigo não contém colesterol: pelo fim das impostoras intelectuais no ensino de ciências. Projeto-Revista de Educação, Porto Alegre, v. 1, n.1, p. 25-34, 1999.

LEITE, M. Biotecnologia, clones e quimeras sob controle social: missão urgente para divulgação científica. São Paulo em Perspectiva, São Paulo, v. 14, n. 3, 2000.

NODARI, O. R.; GUERRA, P. M. Os impactos ambientais. Revista Ciência Hoje, São Paulo, v. 34, n. 203, 2004.

PEDRANCINI, V. D et al. Ensino e aprendizagem de biologia no ensino médio e a apropriação do saber científico e biotecnólogico. Revista eletrônica de Enseñanza de las Cências, Caderno da Biodiversidade, Maringá, v. 6, n. 2, 2007. Disponível em: <http://www.scielo.br/scielo.php? script=sci_arttext\&pid $=$ S1516 73132008000100009\&lng=en\&nrm=iso $>$. Acesso em: 30 jun. 2008.

PEDRANCINI, V, D. et al. Saber científico e conhecimento espontâneo: opiniões de alunos do ensino médio sobre transgênicos. Ciências educação, Bauru, v. 14, n. 1, 2008. Disponível em: $<\mathrm{http}: / /$ www.scielo.br/scielo.php?script=sci_arttext\&pid=S1516-73132008000100009\&lng=en $\& n r m=i s o>$. Acesso em: 30 jun. 2008. 